\title{
SABERES E TRADIÇÃO: A CERÂMICA CAETEUARA DA COMUNIDADE FAZENDINHA
}

\author{
Dione Vieira Salis ${ }^{1}$ \\ Damiana Barros Nascimento ${ }^{2}$ \\ João Paulo Martins Sarmento ${ }^{3}$ \\ Flávio Leonel Abreu Silveira ${ }^{4}$
}

Este ensaio é resultado de uma pesquisa de campo realizada como requisito de avaliação final para a disciplina Antropologia Visual e da Imagem, do Curso de PósGraduação em Linguagens e Saberes na Amazônia. O locus desta experiência foi a Comunidade Fazendinha, situada à margem esquerda do rio Caeté, distante $5 \mathrm{~km}$ da sede do município de Bragança, nordeste paraense.

A Comunidade Fazendinha tem a sua organização sociocultural ligada ao trabalho junto às olarias - e a produção artesanal de diversos tipos de objetos como telhas e tijolos, bem como de utensílios e adornos para a casa, manutenção de roças e a pesca, junto aos cursos d'água da região. Percebe-se a predominância da religiosidade católica, neste caso, com a expressiva devoção à padroeira da localidade: Nossa Senhora do Carmo, mas há, contudo, um forte vínculo dos moradores com São Benedito, o mais popular do município, reverenciado nos festejos da Marujada ${ }^{5}$. Quanto à educação formal, a comunidade dispõe de uma única escola que oferta do $1^{\circ}$ ao $5^{\circ}$ ano do ensino fundamental, o que faz com que os jovens após o término desse nível de ensino tenham que se deslocar da localidade a fim de estudarem em escolas na sede do município.

O ensaio em questão tem por objetivo mostrar alguns aspectos relativos aos saberes e fazeres utilizados na produção de peças cerâmicas artesanais. Neste caso, da chamada cerâmica caeteuara - pois, como dito antes, a comunidade situa-se às margens do rio Caeté -, envolvendo, assim, práticas que são tradicionalmente mantidas desde o surgimento da comunidade.

\footnotetext{
${ }^{1}$ Mestranda do Programa de Pós-Graduação em Linguagens e Saberes na Amazônia, Universidade Federal do Pará/UFPA- Campus Bragança-PA. E-mail: dionesalis@ gmail.com

${ }^{2}$ Mestranda do Programa de Pós-Graduação em Linguagens e Saberes na Amazônia, Universidade Federal do Pará/UFPA- Campus Bragança-PA. E-mail: damicom2@gmail.com

${ }^{3}$ Mestrando do Programa de Pós-Graduação em Linguagens e Saberes na Amazônia, Universidade Federal do Pará/UFPA- Campus Bragança-PA. E-mail: joaoqlegal@yahoo.com.br

${ }^{4}$ Doutor em Antropologia Social. Professor do Programa de Pós-Graduação em Linguagens e Saberes na Amazônia. Universidade Federal do Pará/UFPA- Campus Bragança-PA. E-mail: flabreu@ufpa.br

${ }^{5}$ Marujada: Festa popular, iniciada pelos escravos em 1798, no dia 3 de setembro 2017, comemorou 219 anos.
} 
O percurso metodológico utilizado para a elaboração deste ensaio priorizou visitas a algumas famílias e a coleta de dados, por meio de diálogos e registros fotográficos ${ }^{6}$ a partir de uma rápida, mas intensa, experiência etnográfica de convívio com alguns moradores "da Fazendinha".

Nota-se que a principal atividade econômica da comunidade se configura na produção de cerâmica de tijolos, telhas e artesanatos diversos, produzidos a partir da matéria-prima barro. A produção destes artefatos está ligada à herança e ao repasse de saberes e fazeres vinculados à identificação de áreas, da coleta e do tratamento da argila encontrada, naturalmente, nas paisagens regionais. Neste sentido, de acordo com o Senhor Antônio Maria, a sua experiência pessoal com o manejo da argila remete aos conhecimentos repassados a ele por seu avô, senhor de descendência portuguesa que dominava a arte de manuseá-la, no torno, à época, movido à força humana. Inicialmente, as pessoas faziam peças grandes. Entre elas destacam-se os potes, mas também, sabe-se que produziam canos para tubulações subterrâneas e tijolos utilizados na cidade de Bragança. Atualmente, os artesãos vendem suas produções na localidade, assim como em eventos (feiras artesanais, exposições de cerâmicas) e no comércio bragantino.

Conforme Silva e Costa (2009, p. 86), a economia amazônica baseada na extração de recursos naturais, indica que "a Fazendinha está inserida nesse contexto, e se destaca como importante polo de extração de argila, dentre as 18 comunidades da Bacia do Caeté, que sobrevivem, basicamente, de recursos naturais, tais como, a pesca, a agricultura e o extrativismo". Trata-se, desta forma, de uma prática de manejo da argila que apresenta forte presença regional, portanto, insere-se num conjunto de tradições ligadas a saberes e fazeres que vinculam os seus moradores ao seu lugar de pertencimento (Certeau, 1994), por intermédio das ações modeladoras da matéria (Bachelard,1998), e cujas práticas vêm se transformando ao longo do tempo.

Os relatos dos artesãos quanto à produção das peças elaboradas indicam um complexo jogo social que envolve conhecimentos que dinamizam a cultura local, os quais obedecem às seguintes etapas: primeiramente, retira-se a argila de locais específicos nas paisagens caeteuaras, que após passar por um processo de limpeza manual, a fim de se eliminar qualquer elemento - raiz ou pedaço de pau - que prejudique a feitura da peça, até o ponto de ser encaminhada à modelagem no torno, que pode ser manual, e também, elétrico, como podemos observar no local. Depois de modeladas, as peças passam por um período descanso

\footnotetext{
${ }^{6}$ Todas as imagens foram obtidas pelos autores em diferentes momentos do trabalho de campo.
} 
de aproximadamente dois dias, quando secam em prateleiras. A finalização ocorre com "a queima" dos artefatos nos fornos de barro, existentes nas diversas moradias da Comunidade.

Algumas famílias de artesãos utilizam a semente do urucuri para marcarem as suas peças - o que caracterizaria, em parte, o artesanato local -, além do óleo da andiroba com o qual fazem o acabamento final, quando podem utilizar argilas de diferentes tonalidades.

Outras famílias, por sua vez, utilizam grafismos feitos manualmente para decorar as peças confeccionadas. Estes elementos, que seriam característicos da região, contribuem para criar certa identidade artesanal, que seria uma referência àquela comunidade em particular, que merece ser melhor estudado.

Finalmente, considerando os saberes adquiridos e utilizados na produção das peças artesanais da cerâmica caeteuara produzidas na Comunidade Fazendinha, percebemos que a tradição resulta da sensibilidade própria à "imaginação criadora"7 dos artesãos, materializada no gesto de modelar a argila, e que se expressa enquanto uma forma ético-estética - porque tanto aponta para o sentimento quanto às relações de estarem juntos - dos habitantes da localidade na confecção de coisas, quanto uma narrativa imagética ligada a essas mesmas coisas cuja sensibilidade nos afeta (Favret-Saada, 2005) e reverberam em nossas formas de perceber a artes do fazer na Amazônia, intimamente ligadas ao cotidiano das famílias que constituem a Comunidade da Fazendinha, no contexto do Salgado Paraense.

\section{REFERÊNCIAS BIBLIOGRÁFICAS}

BACHELARD, G. A Poética do Espaço. São Paulo: Martins Fontes, 1988.

CERTEAU, M. de. A Invenção do Cotidiano. Artes de fazer. V. 1. Rio de Janeiro: Vozes, 1994.

FAVRET-SAADA, J. Ser afetado. Cadernos de Campo, São Paulo, 13, 155-161, 2005.

ROCHA, A. L. C. "Antropologia das formas sensíveis: entre o visível e o invisível, a floração de símbolos”. Horizontes Antropológicos, 1(2): 85-92, 1995.

SILVA, I. R.. ; COSTA, L.P. R. M. Exploração de Argila em Fazendinha e os Impactos Socioambientais (Amazônia, Brasil) Revista de Gestão Costeira Integrada, 9(2):85-90 (2009). < Disponível em www.aprh.pt/rgci/pdf/rgci-119_Silva.pdf> Acesso dia 30 de agosto de 2017.

\footnotetext{
${ }^{7}$ Para usarmos uma imagem bachelardiana utilizada por Rocha (1995).
} 

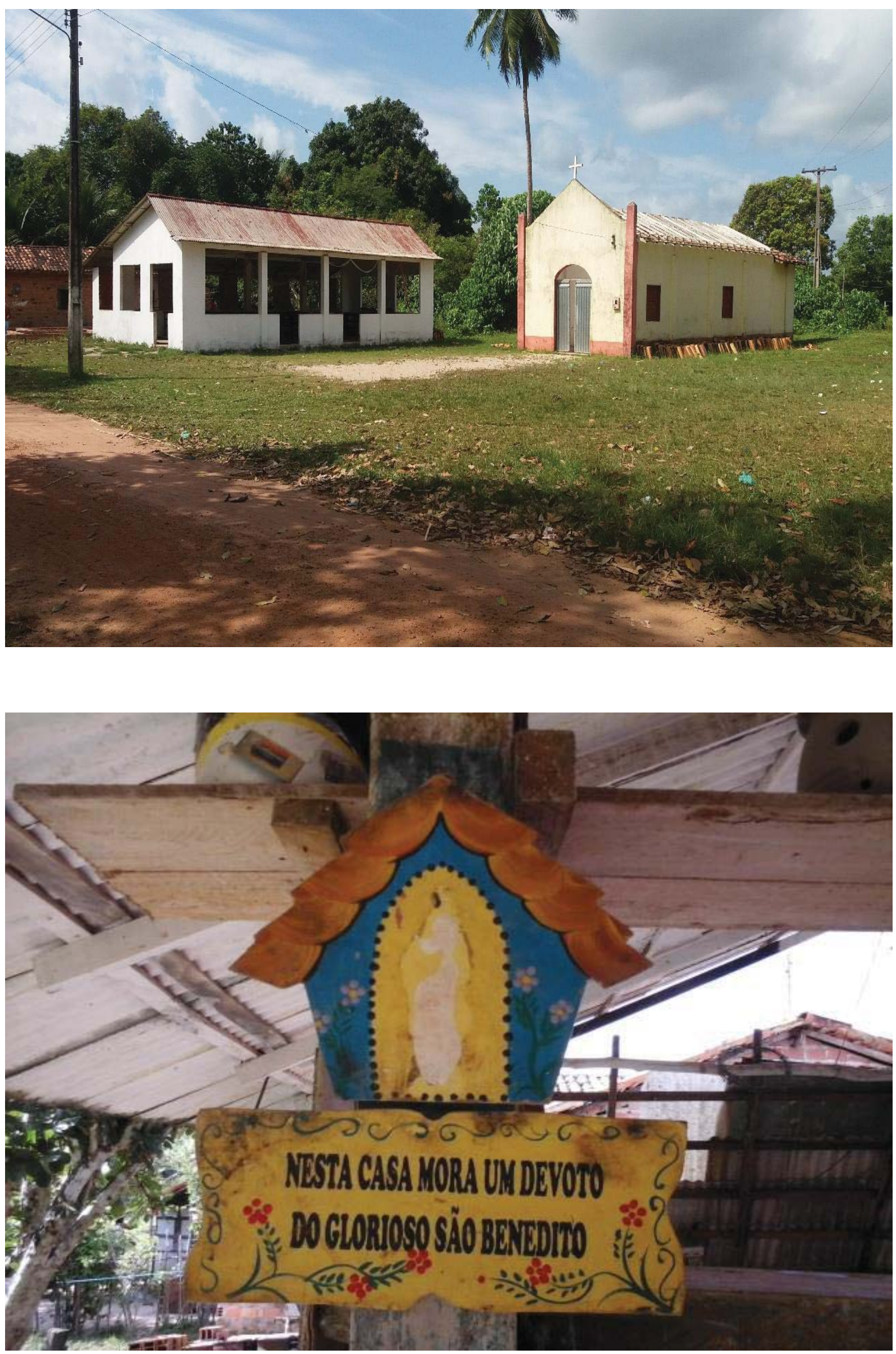

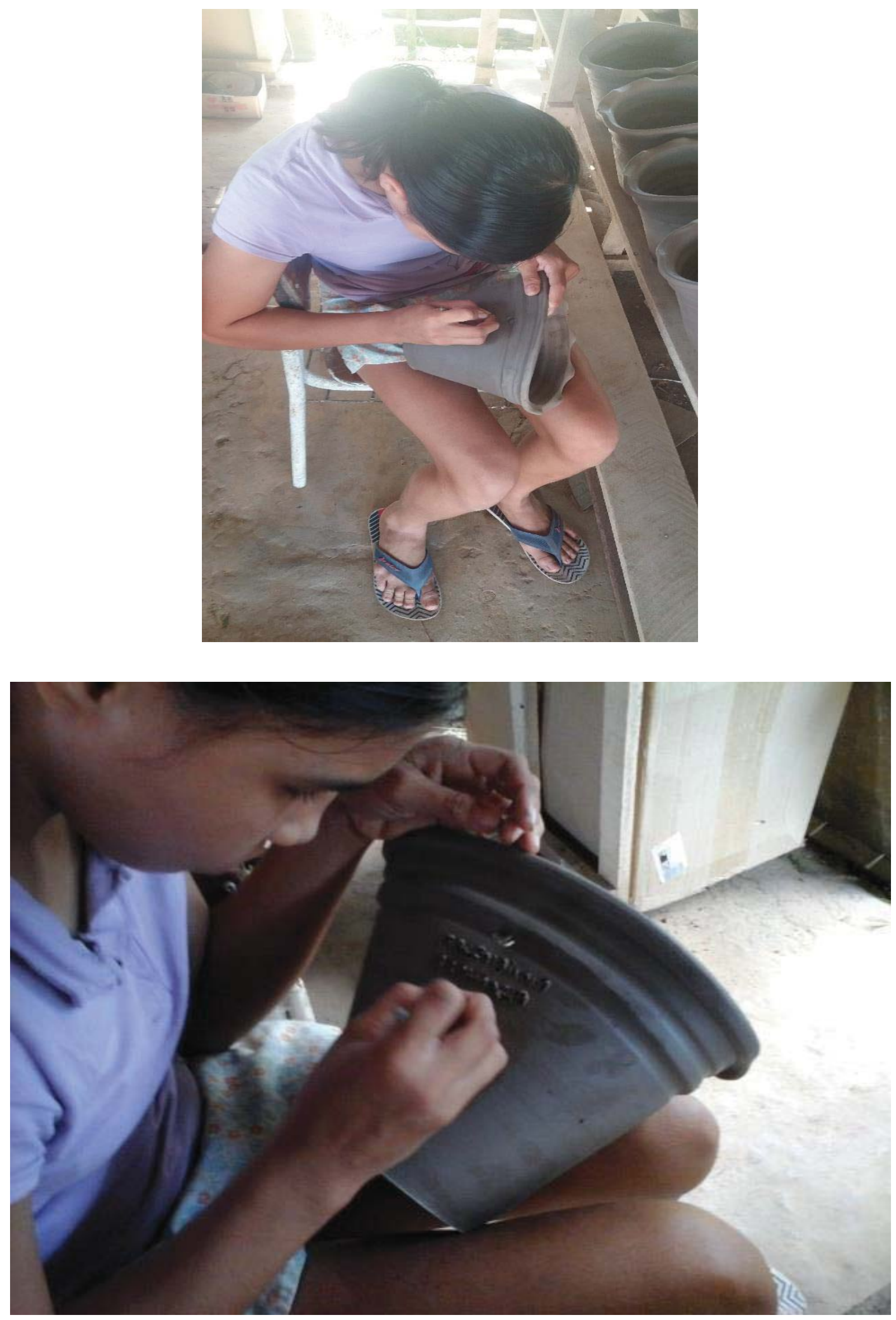

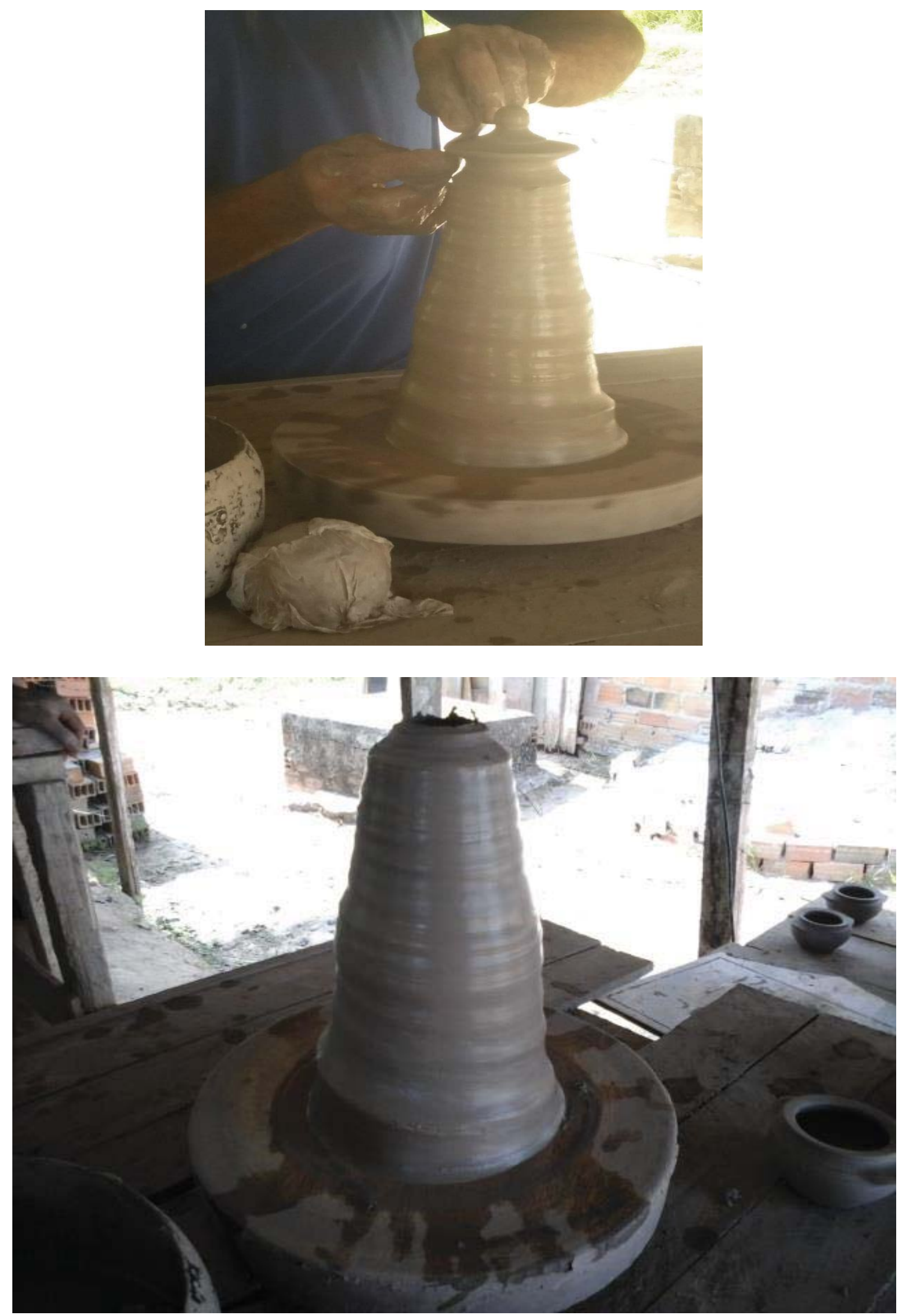

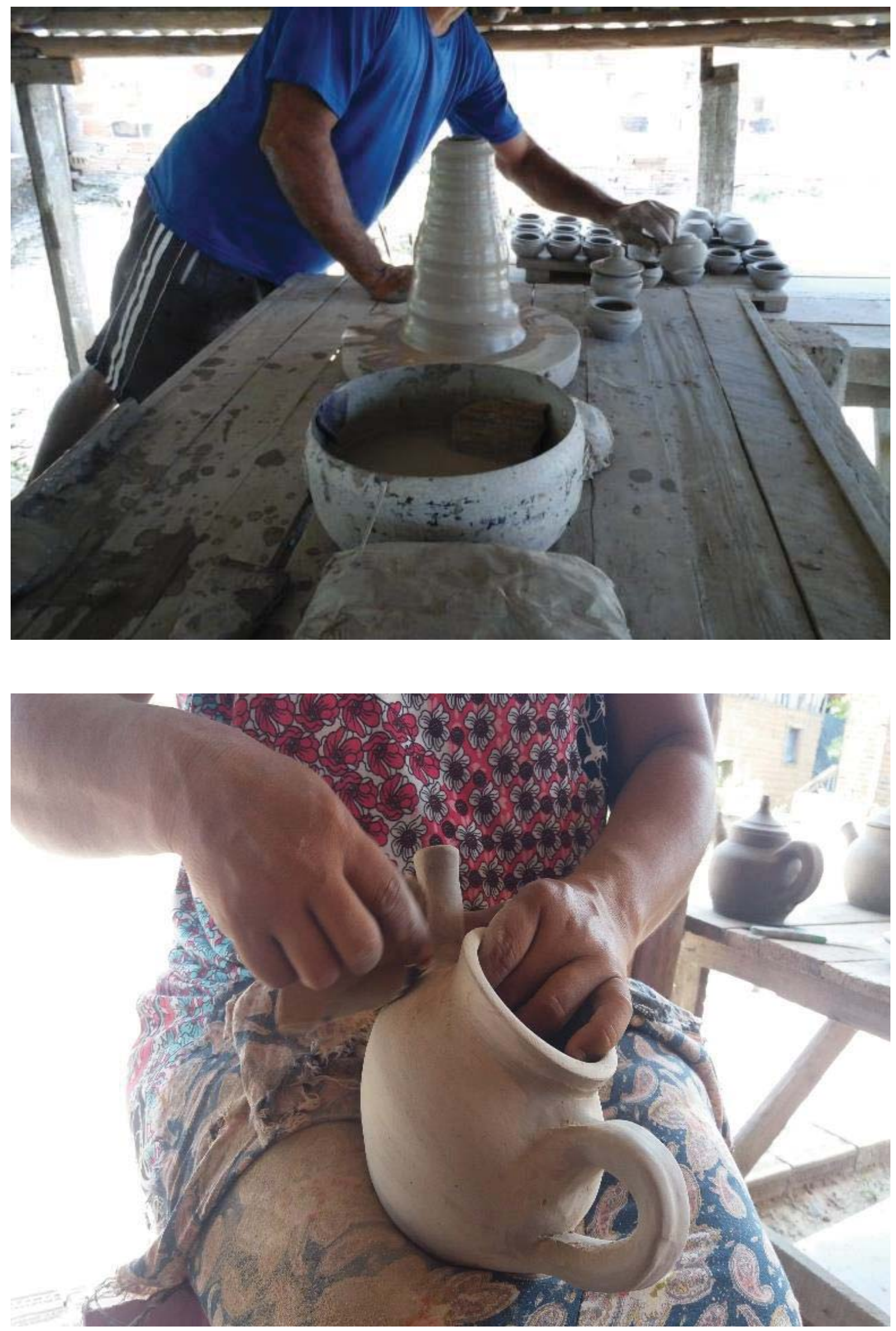

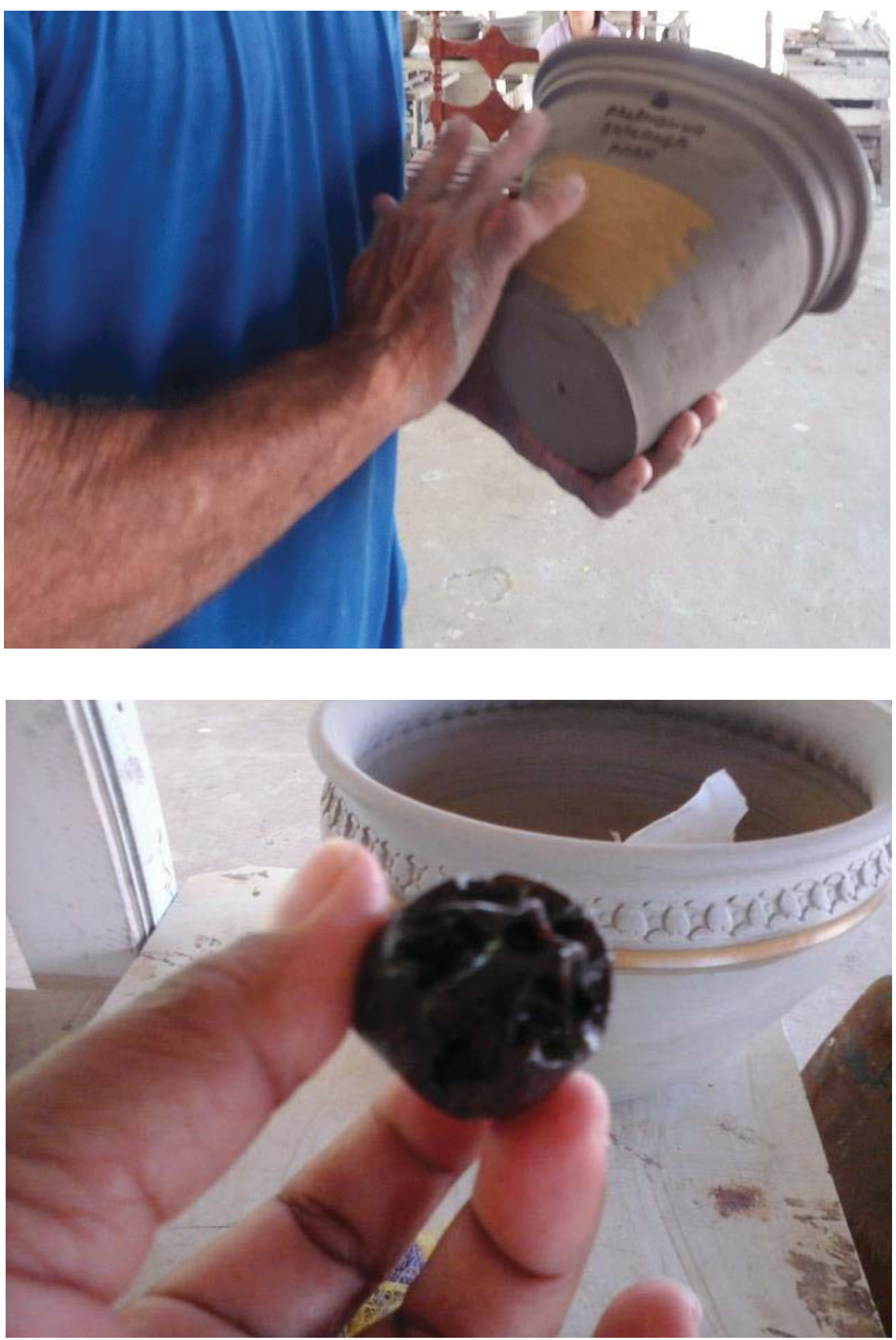

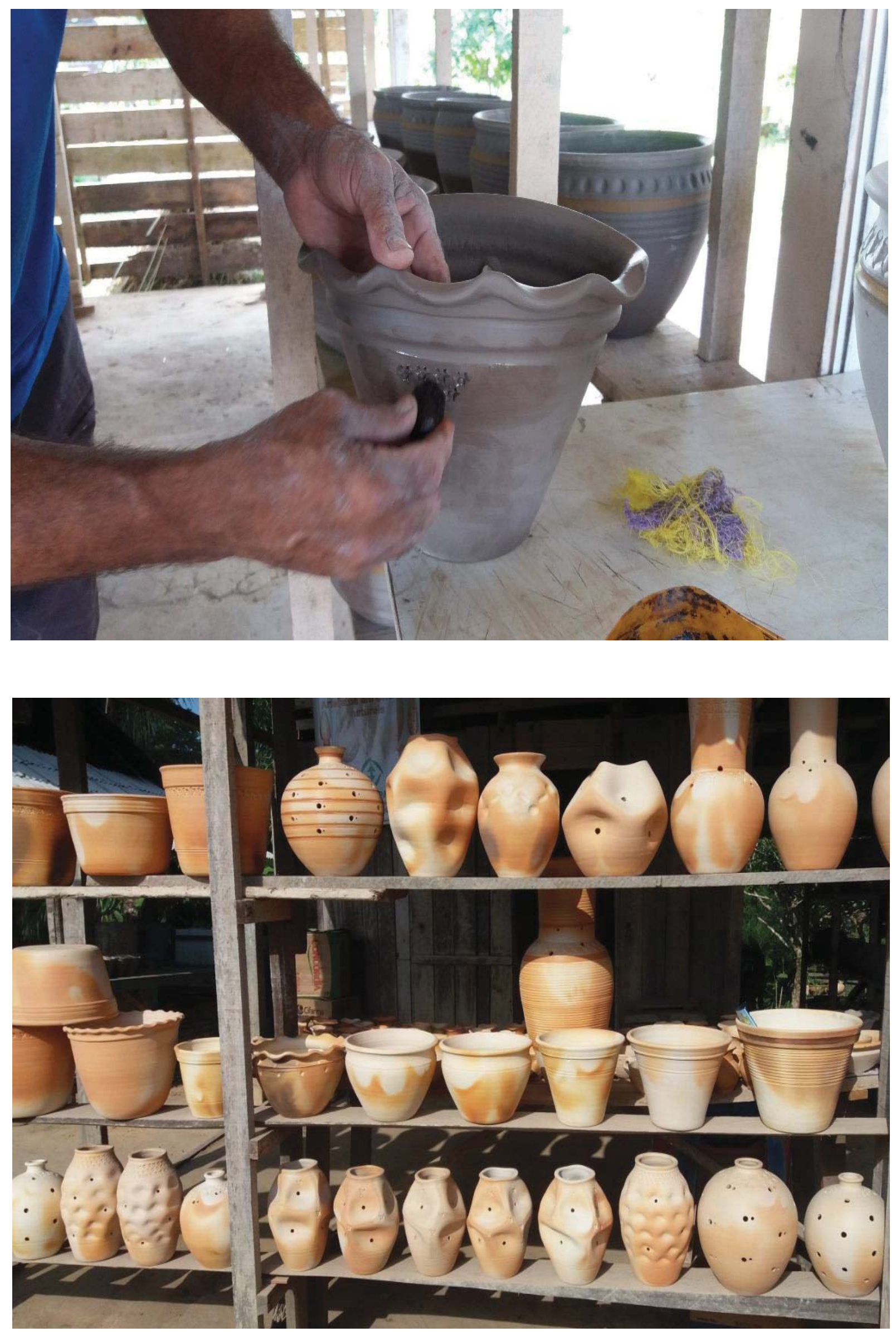

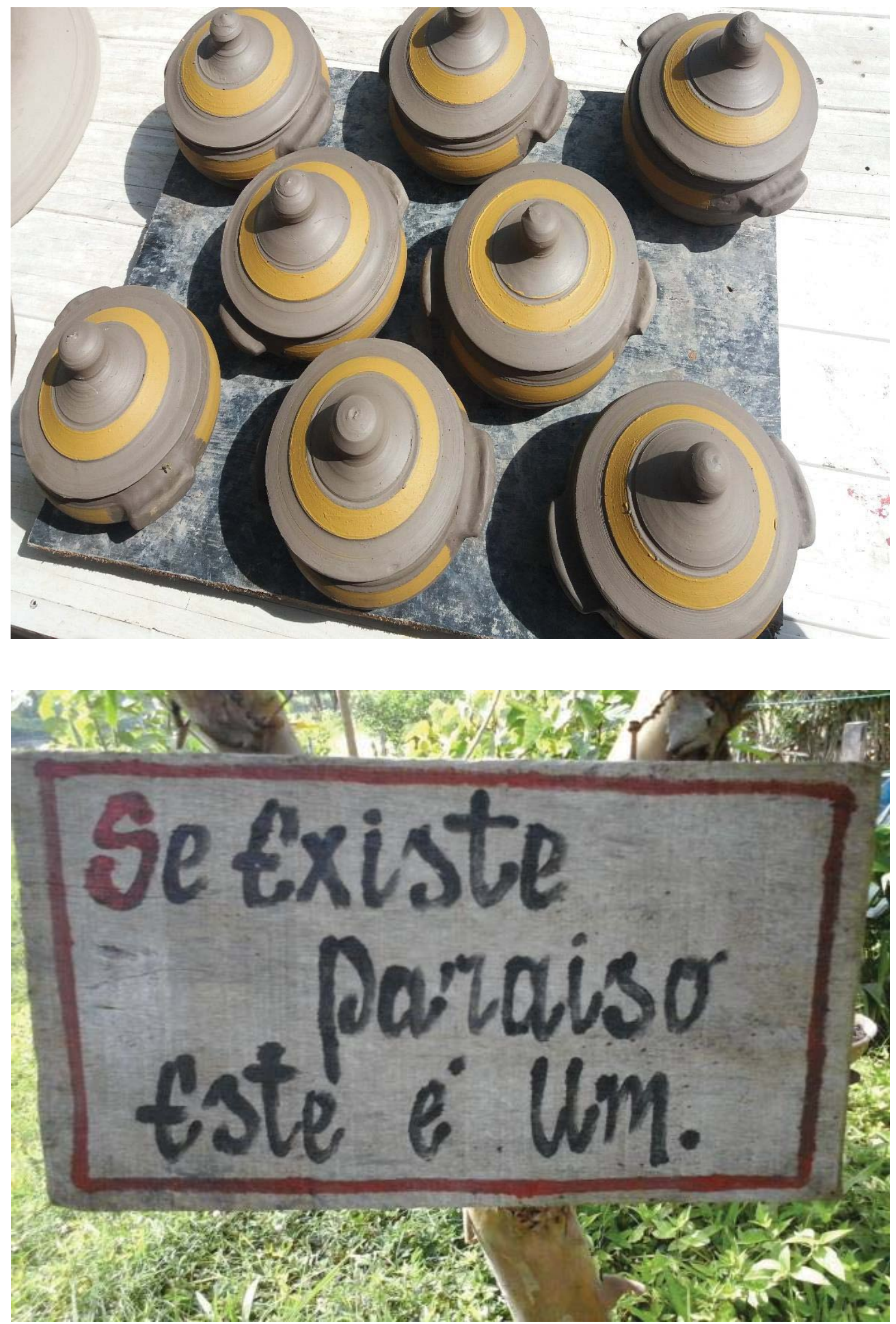